\title{
BMJ Global Health Building a multisystemic understanding of societal resilience to the COVID-19 pandemic
}

Didier Wernli (D , , ${ }^{1}$ Mia Clausin, ${ }^{1}$ Nino Antulov-Fantulin, ${ }^{2}$ John Berezowski, ${ }^{3}$ Nikola Biller-Andorno (D) , ${ }^{4}$ Karl Blanchet (D) , ${ }^{5}$ Lucas Böttcher, ${ }^{6}$ Claudine Burton-Jeangros, ${ }^{7}$ Gérard Escher, ${ }^{8}$ Antoine Flahault, ${ }^{9}$ Keiji Fukuda, ${ }^{10}$ Dirk Helbing, ${ }^{2}$ Philip D Jaffé, ${ }^{11}$ Peter Søgaard Jørgensen, ${ }^{12,13}$ Yuliya Kaspiarovich, ${ }^{1}$ Jaya Krishnakumar, ${ }^{14}$ Roderick John Lawrence, ${ }^{15}$ Kelley Lee (D) ,16 Anaïs Léger, ${ }^{1}$ Nicolas Levrat, ${ }^{1,17}$ Romain Martischang, ${ }^{18}$ Chantal M Morel (D) , 'Didier Pittet, ${ }^{18}$ Maxime Stauffer, ${ }^{19,20}$ Fabrizio Tediosi, ${ }^{21,22}$ Flore Vanackere, ${ }^{1}$ Jean-Dominique Vassalli, ${ }^{23,24}$ Gaélane Wolff, ${ }^{25}$ Oran Young ${ }^{26}$
To cite: Wernli D, Clausin M, Antulov-Fantulin N, et al. Building a multisystemic understanding of societal resilience to the COVID-19 pandemic. BMJ Global Health 2021;6:e006794. doi:10.1136/ bmjgh-2021-006794

Received 2 July 2021 Accepted 7 July 2021
Check for updates

(c) Author(s) (or their employer(s)) 2021. Re-use permitted under CC BY-NC. No commercial re-use. See rights and permissions. Published by BMJ

For numbered affiliations see end of article.

Correspondence to Dr Didier Wernli; didier.wernli@unige.ch

\section{ABSTRACT}

The current global systemic crisis reveals how globalised societies are unprepared to face a pandemic. Beyond the dramatic loss of human life, the COVID-19 pandemic has triggered widespread disturbances in health, social, economic, environmental and governance systems in many countries across the world. Resilience describes the capacities of natural and human systems to prevent, react to and recover from shocks. Societal resilience to the current COVID-19 pandemic relates to the ability of societies in maintaining their core functions while minimising the impact of the pandemic and other societal effects. Drawing on the emerging evidence about resilience in health, social, economic, environmental and governance systems, this paper delineates a multisystemic understanding of societal resilience to COVID-19. Such an understanding provides the foundation for an integrated approach to build societal resilience to current and future pandemics.

\section{RESILIENCE OF WHOM TO WHAT?}

The ecological, economic and social complexity of global societal challenges is the linchpin of the COVID-19 pandemic. ${ }^{1}$ High levels of connectivity and coupling in a globalised world created pathways for the initial manifestations of the crisis to propagate and amplify. ${ }^{2}$ The COVID-19 pandemic and its associated responses have interfered broadly with human activities and have generated wide-ranging systemic effects in health, economic, social, environmental and governance systems worldwide. Not all societies have been affected in the same way. Disruptions were particularly severe in countries that were unable to control widespread community transmission. Prior assessment of countries'

\section{Summary box}

The COVID-19 pandemic has tested resilience in health but also social, economic, environmental and governance systems across the world.

- Progress has been made in recent years to define and assess health system resilience, but broader societal resilience to emerging infectious diseases is not well defined.

- Societal resilience to the current COVID-19 pandemic relates to the ability of societies to maintain their core functions while minimising the health impact of the pandemic and other societal effects.

- Developing evidence about resilience in different systems will serve as the foundation for an integrated approach to build societal resilience to COVID-19 and future pandemics. 


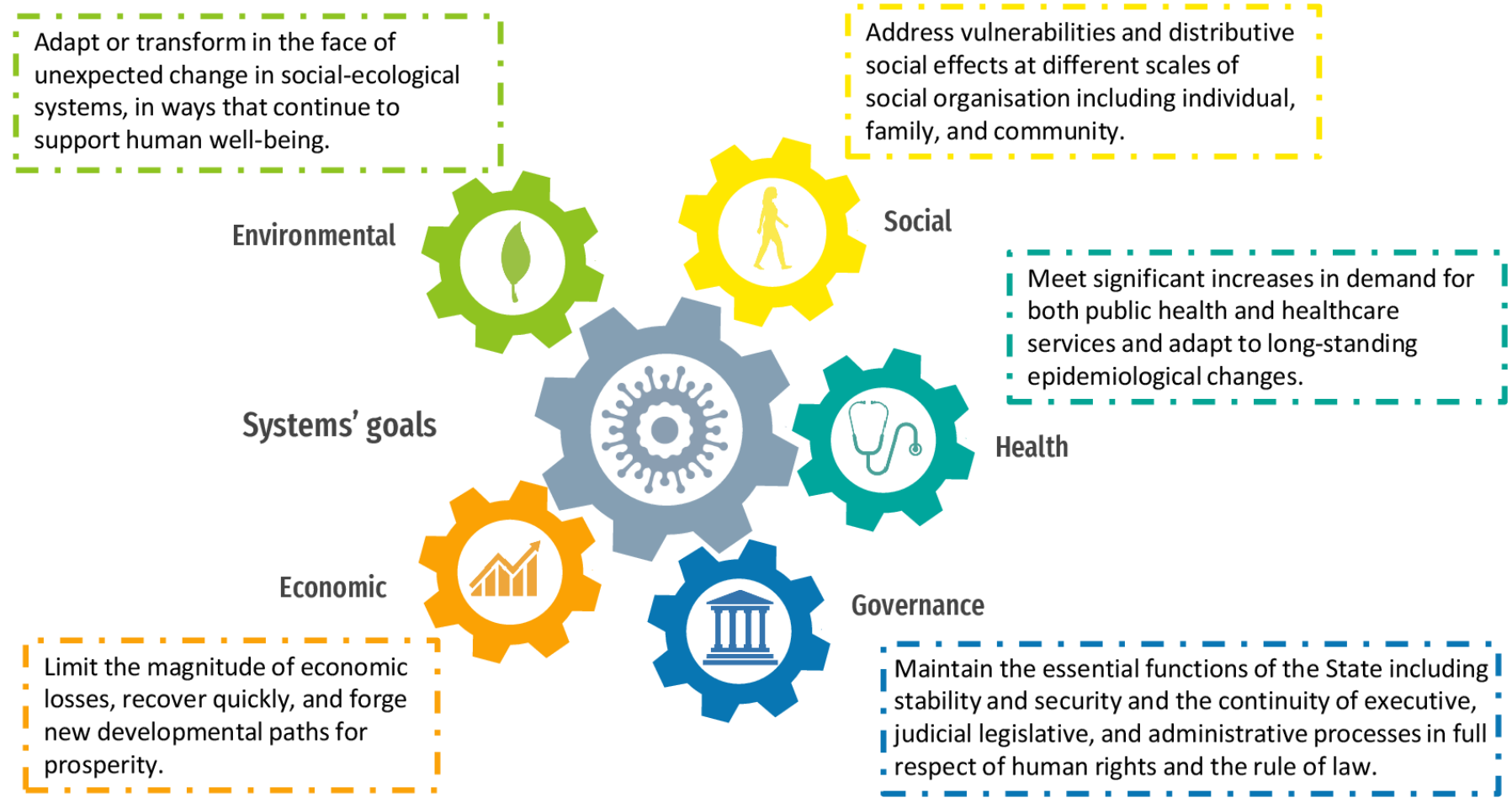

Figure 1 Interconnected societal systems and their different goals in addressing the COVID-19 pandemic.

governance functions and minimising any undesirable systemic effects. This definition encompasses the capacities of societies to (1) prepare, prevent and protect before disruption; (2) mitigate, absorb and adapt during disruptions; and (3) restore, recover and transform after disruption. ${ }^{6}$

The world consists of highly composite systems whose interacting parts give rise to a behaviour that is more than the sum of the parts. From single organisms to ecosystems, communities and whole societies, these organised wholes are called 'complex adaptive systems'. Contemporary societies are usually organised into several and sometimes overlapping complex adaptive systems, based on societal sectors such as health, the economy and the environment. Societal resilience thereby relates to the effectiveness of the response across different sectoral systems, which have distinct rules, expertise and institutions. Another element is the resilience of governance systems to ensure an effective, legitimate and accountable response. From a multisystemic perspective, a striking challenge of the COVID-19 pandemic is managing trade-offs between systems that have different goals (figure 1). In this paper, we seek to define resilience in the health, economic, social, environmental and governance systems. For each system, we provide examples of how resilience has been expressed at different scales of social organisation. A multisystemic approach can help understand how societies as a whole are affected by and react to systemic crises. This in turn provides the basis for the development of integrated approach to foster resilience to pandemics.

\section{RESILIENCE IN DIFFERENT SYSTEMS}

Health resilience encompasses capacities at several scales of social organisation to promote, restore and maintain health when confronted with a shock. ${ }^{8}$ A first challenge of SARS-CoV-2 and its various variants relates to their high transmissibility. Second, the absence of immunity to SARS-CoV-2 in the population makes a proportion of the population, the size of which is influenced by different risk factors, susceptible to severe infections and deaths. ${ }^{9}$ Health resilience to the COVID-19 pandemic is thus broadly referred to the capacities to prevent or reduce both transmission and mortality of SARS-CoV-2. Preventing transmission primarily involves actions to reduce exposure to SARS-CoV-2. At the individual and community levels, this means making informed decisions that protect themselves and others (eg, physical distancing, wearing a mask and reducing the number of close contact interaction with others). Furthermore, resilience derives from the capacity of public health authorities to prevent and slow down transmission by implementing contact tracing, case isolation and quarantine. Experiences in several countries across the world have shown that rapid actions are largely successful in preventing community transmission. ${ }^{10}$ When they were not, community transmission leads to a surge of patients in healthcare systems. Healthcare resilience to the COVID-19 pandemic relies primarily on how hospitals cope with a surge of patients and, when capacities are exceeded, adapt through reorganisation and an appropriate and timely allocation of resources. ${ }^{11}$ Finally, the COVID-19 pandemic also underlines the contribution of other stakeholders to resilience. Vaccines developed 
by the pharmaceutical industry increase resilience by reducing transmission, morbidity and mortality. ${ }^{12}$ Finally, a critical issue underpinning global health resilience is improved coordinated country efforts to address the short-term and long-term health needs of all while limiting further disruptions linked to COVID-19.

Social resilience is the capacity of societies to maintain their core social functions and reduce the social impact of a shock. It involves different scales of social organisation including individuals, families, communities and societies. ${ }^{13}$ The COVID-19 pandemic has exposed people and communities to a complex array of stressors with worrying implications for mental health and a widening of economic and social inequalities. ${ }^{14}$ Individual resilience might be shaped by factors as diverse as personality traits, lifestyles and social support. ${ }^{15}$ In countries that adopted lockdowns to curb the COVID-19 pandemic, a strategy for social resilience was to allow the mixing of a limited number of people through the introduction of a family bubble. ${ }^{16}$ Adaptation to school closure in many countries came at the price of an exacerbation of gender inequalities with women bearing the brunt of the work related to children being out of school. ${ }^{17}$ Educational continuity was ensured by virtual class in several parts of the world, but the shift to online learning might have impacted those coming from a disadvantaged socioeconomic background. ${ }^{18}$ Social resilience to the pandemic also emphasised the role of communities in supporting core social functions. Voluntary action and mutual aid have been stepped up to aid the most vulnerable, for example, for emergency transport, food shopping and emotional support. ${ }^{19}{ }^{20}$ Given the wider social effects of the crisis, an important source of resilience was the introduction and enhancement of social protection measures by the state. ${ }^{21}$ Addressing the long-term social effects of the COVID-19 pandemic, including worsened mental health, inequalities and poverty, is likely to be the most important issue for social resilience in the recovery phase.

Economic resilience rests on limiting the magnitude of economic losses, recovering quickly and forging new developmental paths for prosperity. ${ }^{22}$ Resilience first concerns how individuals and households cope with economic hardship by using their existing financial resources and modifying their behaviours. ${ }^{23}$ In countries lacking a safety net, lockdown measures prevented people from earning a basic income and/or forced them to use their lifelong savings. ${ }^{24}$ Individuals in precarious labour conditions were often employed in the sectors of the economy most affected by the pandemic, such as retail, culture, hospitality and tourism. As such, social welfare including unemployment benefits, paid sick leave schemes, health insurance and food distribution mitigated the economic impact on households. ${ }^{25}$ At the firm level, the size, position and centrality of firms in supply chain networks notably influenced the impact of disruptions. ${ }^{26}$ The production of globally connected firms was more likely to be affected by disruptions in global supply chains. ${ }^{27}$ At the same time, globally connected firms, which often have the most market power, were less prone to liquidity problems than small-sized and medium-sized businesses. ${ }^{28} 29$ As an important risk for companies was to become insolvent, resilience relied on governmental support such as loans, subsidies and deferrals of taxes. ${ }^{30}$ To avoid a sharp rise in unemployment, financial assistance to businesses was further increased in the form of benefits for employees or partial unemployment compensation schemes. Macroeconomic resilience is concerned with how different sectors and countries were able to limit and recover from the magnitude of the economic shock. ${ }^{31}$ Elimination strategies as opposed to mitigation strategies have been more economically viable. ${ }^{32}$ While many countries experienced a marked economic decline with a shock affecting both supply and demand, a country's resilience is likely to be influenced by its fiscal space and ability to borrow money to pay for financial support. Key issues for economic resilience include how fast countries will recover from the shock and how they will manage the issue of debt sustainability over the long term.

The COVID-19 pandemic has had both positive and negative impacts on the environment. ${ }^{33}$ Ecological resilience is defined as 'a measure of the persistence of systems and of their ability to absorb change and disturbance and still maintain the same relationships between populations or state variables ${ }^{34}$ In this case, the slowdown of human activities during lockdowns led to a reduction of their impact on nature. With people at home, nature was quick to return to cities, particularly during the most stringent lockdowns during the first half of $2020 .^{35} \mathrm{It}$ is unclear yet how connectedness with nature has been impacted by the pandemic. The COVID-19 may lead to a better awareness of the impact of anthropogenic activities on nature. ${ }^{36} \mathrm{In}$ addition, the COVID-19 pandemic has been an opportunity to accelerate some pre-existing trends regarding the protection of the environment. Many local governments prioritised support for the greener economy including measures to promote cleaner transportation and the creation of bicycle lanes in urban areas. ${ }^{37}$ The COVID-19 pandemic also re-emphasised the importance of urban agriculture as a way to strengthen local food production and create resilience to shock affecting food production. ${ }^{38}$ The global reduction in human activities led to a transitory reduction of daily emissions of $\mathrm{CO}_{2}$. A study estimated that from January to June 2020, global $\mathrm{CO}_{2}$ emissions were reduced by $8.8 \%$ compared with the same period in 2019. ${ }^{39}$ However, the positive environmental impact of the pandemic was limited given the current trends towards climate change. ${ }^{40}$

The COVID-19 pandemic has challenged the normal functioning of governance systems. The resilience of the governance system to an external shock such as the COVID-19 pandemic depends on the capacity of the state to maintain its core functions while supporting the response to the shock. When the public health response was not able to effectively curb transmission, many governments introduced wide-ranging measures, 
which were effective at reducing the health impact of the COVID-19 pandemic in different countries. ${ }^{41}$ However, the deployment of 'emergency powers' radically challenged the rule of law and the fundamental rights and freedoms (eg, freedoms of movement and assembly and right to privacy) that underpin the fabric of many societies. ${ }^{42}$ For example, many democracies were slow to react to the first and subsequent waves due to their reluctance to impose interventions that encroached on civil liberties. ${ }^{43}$ However, some governments used the response to the COVID-19 pandemic to accelerate an authoritarian and illiberal agenda. ${ }^{44}$ In addition to impacting human rights, ${ }^{45}$ the scale and scope of the response to the COVID-19 pandemic challenged the proper functioning of institutions. For example, campaigning, elections and participation in formal and informal deliberation were affected by the COVID-19 pandemic in some countries. ${ }^{46}$ Resilience came partly from a shift to online activities and socially distanced solutions such as online campaigning or postal voting, although these were sometimes tainted by logistical challenges. ${ }^{47}$ While the COVID-19 pandemic reaffirms the importance of sound governance, some countries managed to balance crisis government capacity and legitimacy thanks to inclusive decision-making, transparent communication and a high level of citizen trust in government. ${ }^{48}$ Recovery resilience of the governance system will revolve around countries' abilities to restore precrisis governance modus operandi based on the rule of law, balance of powers and deliberative processes.

\section{IMPROVING OUR UNDERSTANDING OF MULTISYSTEMIC RESILIENCE}

Our analysis suggests that the COVID-19 pandemic tested resilience in sectoral systems and governance systems across several scales of social organisation. The pandemic and its associated responses resulted in both negative and positive outcomes, an intrinsic feature of complex systems. Societal resilience to the COVID-19 pandemic can be visualised as multilayered network, characterised by interactions among and between factors across systems, scales of social organisation and levels of governance (figure 2). At the country level, resilience's capacities are likely to be influenced by the variation in the level of socioeconomic development in different countries. For example, sustaining a mitigation strategy poses several challenges in low- and middle-income countries (LMIC), which often lack a safety net. Poor households are prone to experience food insecurity. ${ }^{49}$ In addition, the capacity to borrow money on financial markets to

\section{Social organisation scales}

\section{Governance levels}

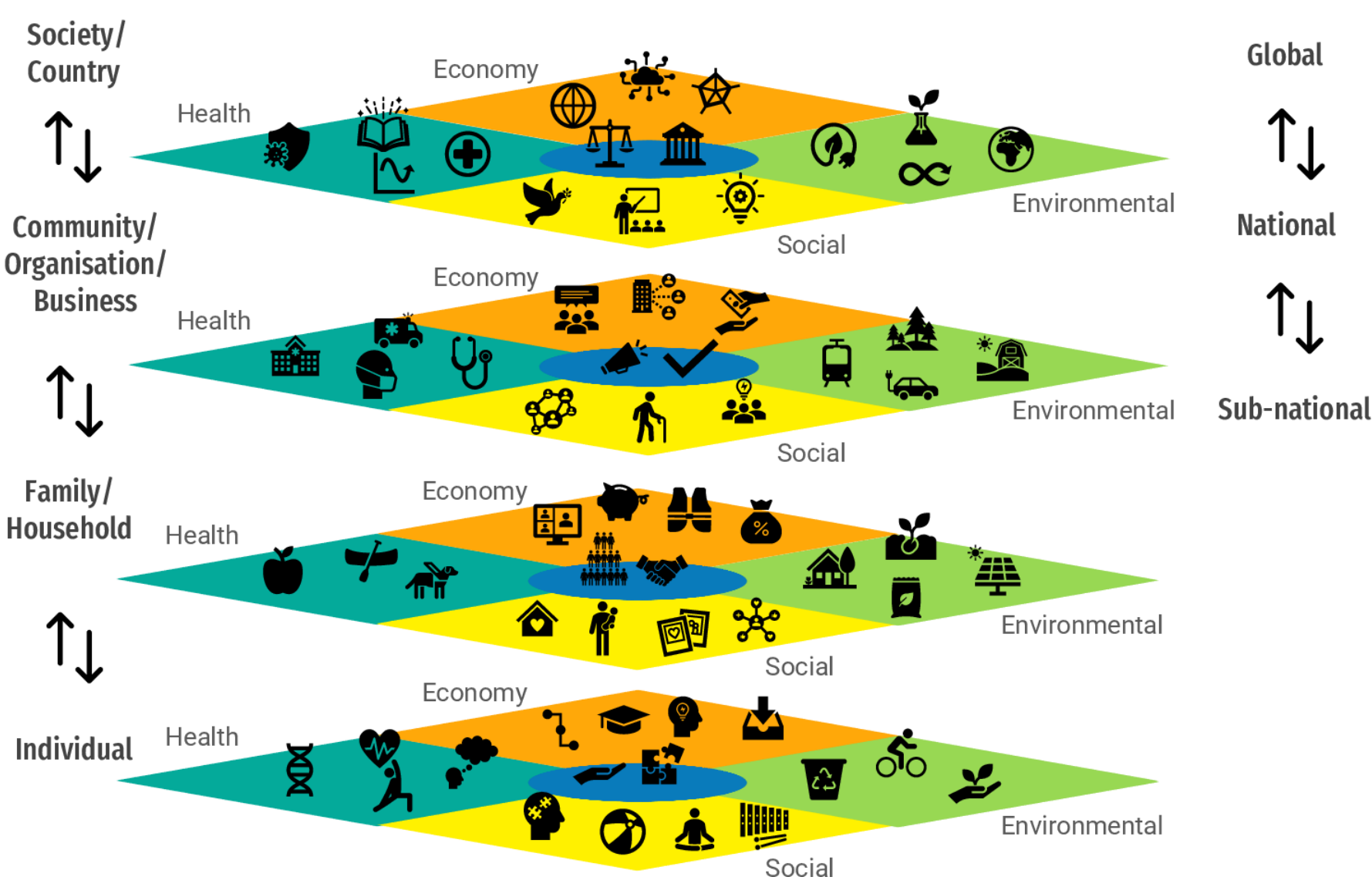

Figure 2 Resilience to the COVID-19 pandemic as a multi-layered network of interconnected drivers and systems at every social organisation scale and governance level. 
support the economy is limited in many LMIC compared with high-income countries. Overall, there are several key challenges related to building a multisystemic resilience approach to systemic crises such as the COVID-19 pandemic.

A first challenge concerns our mental model regarding the COVID-19 pandemic. Resilience in one system such as the health system is often studied independently from the resilience of other systems. This approach is necessary but tends to overlook the interconnectedness of resilience across systems, which is highly important when we face a systemic crisis such as the COVID-19 pandemic. For example, social resilience is closely entwined with health and economic resilience, as economic crises have long-term consequences on social conditions and public health. ${ }^{50}$ To support a multisystemic approach, we need a better understanding of specific national strengths and vulnerabilities to a range of systemic shocks.

A second challenge is understanding the role and participation of different stakeholders in the response. The literature has identified the importance of national governments regarding the capacity to quickly adopt, adapt and maintain public health and social measures to mitigate the effects of the crisis. However, societal resilience results from the combination of actions at multiple scales of social organisation. This stresses the need for a holistic approach to governance, which can be difficult to implement and sustain when priorities collide.

Third, fostering resilience in different systems relies on society's capacities and willingness to learn and adapt in light of the coevolutionary nature of the COVID-19 pandemic, as illustrated by the emergence of new variants of SARS-CoV-2. The key guiding governance principle should be to maximise the fit between the governance system and the complex nature of the global challenges of the 21st century. ${ }^{51}$ This requires a long-term governance agenda, which may be difficult to balance with the current focus on short-term performance.

\section{CONCLUSION}

In conclusion, we argue that a multisystemic approach to assess societal resilience to the COVID-19 pandemic is vital to address the complexities and uncertainties that underpin global health crises in the 21st century. Our analysis suggests that building resilience to pandemics goes beyond health systems and encompasses social, economic, environmental and governance systems. In other words, societal resilience is an emergent property of complex systems that results from interactions across different scales of social organisation and levels of governance. This framework provides the building blocks for a research agenda, which assesses enablers of and obstacles to resilience across different systems. Ultimately, our analysis underlines the need for careful and critical reflection on how governance can be designed to foster societal resilience to pandemics and other systemic crises. Drawing on the identification of sound and effective actions in different systems, a multisystemic approach to governance should facilitate the integration of different types and sources of knowledge, help address trades-offs between systems and ultimately improve global health.

\section{Author affiliations}

${ }^{1}$ Geneva Transformative Governance Lab, Global Studies Institute, University of Geneva, Geneva, Switzerland

${ }^{2}$ Computational Social Science, ETH Zurich, Zurich, Switzerland

${ }^{3}$ Vetsuisse Faculty, Veterinary Public Health Institute, University of Bern, Bern,

Switzerland

${ }^{4}$ Institute of Biomedical Ethics and History of Medicine, University of Zurich, Zurich, Switzerland

${ }^{5}$ Geneva Centre of Humanitarian Studies, Faculty of Medicine, University of Geneva and Graduate Institute of International and Development Studies, Geneva, Switzerland

${ }^{6}$ Computational Medicine, UCLA, Los Angeles, California, USA

${ }^{7}$ Department of Sociology, School of Social Sciences, University of Geneva, Geneva, Switzerland

${ }^{8}$ Swiss Federal Institute of Technology, Lausanne, Switzerland

${ }^{9}$ Institute of Global Health, Faculty of Medicine, University of Geneva, Geneva,

Switzerland

${ }^{10}$ School of Public Health, Faculty of Medicine, University of Hong Kong, Hong Kong, People's Republic of China

${ }^{11}$ Interfaculty Center for Children's Rights Studies, Faculty of Psychology and Education, University of Geneva, Geneva, Switzerland

${ }^{12}$ Stockholm Resilience Centre, Stockholm, Sweden

${ }^{13}$ Global Economic Dynamics and the Biosphere, Royal Swedish Academy of Sciences, Stockholm, Sweden

${ }^{14}$ Institute of Economics and Econometrics, Geneva School of Economics and Management, University of Geneva, Geneva, Switzerland

${ }^{15}$ Institute for Environmental Sciences, Geneva School of Social Sciences, University of Geneva, Geneva, Switzerland

${ }^{16}$ Faculty of Health Sciences, Simon Fraser University, Burnaby, British Columbia, Canada

${ }^{17}$ Faculty of Law, University of Geneva, Geneva, Switzerland

${ }^{18}$ Infection Control Programme, University of Geneva Hospitals and Faculty of

Medicine, Geneva, Switzerland

${ }^{19}$ Geneva Science Policy Interface, University of Geneva, Geneva, Switzerland

${ }^{20}$ Simon Institute for Longterm Governance, Geneva, Switzerland

${ }^{21}$ Swiss Tropical and Public Health Institute, Basel, Switzerland

${ }^{22}$ University of Basel, Basel, Switzerland

${ }^{23}$ Faculty of Medicine, University of Geneva, Geneva, Switzerland

${ }^{24}$ International Institute for the Rights of the Child, Sion, Switzerland

${ }^{25}$ Global Studies Institute, University of Geneva, Geneva, Switzerland

${ }^{26}$ Bren School of Environmental Science and Management, University of California Santa Barbara, Santa Barbara, California, USA

Twitter Karl Blanchet @BlanchetKarl, Antoine Flahault @FLAHAULT and Kelley Lee @profplum8

Acknowledgements The authors would like to thank all the participants in a workshop held at the Fondation Brocher, Geneva, Switzerland, on 26 September 2020.

Contributors DW did the background research, developed the successive drafts of the paper and designed figure 2. MC designed figure 1. All coauthors contributed content and comments to the paper.

Funding The development of this paper was partly funded through a grant from the Geneva Science Policy Interface (https://gspi.ch/). The paper has been written within the scope of the COVID-19 systemic project (Grant 31CA30_196396; https:// data.snf.ch/covid-19/snsf/196396), which is funded by the Swiss National Science Foundation.

Competing interests None declared.

Patient consent for publication Not required.

Provenance and peer review Not commissioned; internally peer reviewed.

Data availability statement There are no data in this work

Open access This is an open access article distributed in accordance with the Creative Commons Attribution Non Commercial (CC BY-NC 4.0) license, which 
permits others to distribute, remix, adapt, build upon this work non-commercially, and license their derivative works on different terms, provided the original work is properly cited, appropriate credit is given, any changes made indicated, and the use is non-commercial. See: http://creativecommons.org/licenses/by-nc/4.0/.

\section{ORCID iDs}

Didier Wernli http://orcid.org/0000-0002-1751-1961

Nikola Biller-Andorno http://orcid.org/0000-0001-7661-1324

Karl Blanchet http://orcid.org/0000-0003-0498-8020

Kelley Lee http://orcid.org/0000-0002-3625-1915

Chantal M Morel http://orcid.org/0000-0003-3984-9741

\section{REFERENCES}

1 Wernli D, Tediosi F, Blanchet K, et al. A complexity lens on the COVID-19 pandemic. Int J Health Policy Manag 2021. doi:10.34172/ ijhpm.2021.55. [Epub ahead of print: 26 May 2021] (published Online First: $2021 / 06 / 15)$.

2 Helbing D. Globally networked risks and how to respond. Nature 2013;497:51-9.

3 Abbey EJ, Khalifa BAA, Oduwole MO, et al. The global health security index is not predictive of coronavirus pandemic responses among organization for economic cooperation and development countries. PLoS One 2020;15:e0239398.

4 Folke C. Resilience (Republished). Ecology and Society 2016;21:1-30

5 Ungar M. Multisystemic resilience: adaptation and transformation in contexts of change. USA: Oxford University Press, 2021.

6 Linkov I, Trump BD. The science and practice of resilience. Berlin: Springer, 2019.

7 Thurner S, Klimek P, Hanel R. Introduction to the theory of complex systems. Ebook ed. Oxford: Oxford University Press, 2018.

8 Wulff $\mathrm{K}$, Donato $\mathrm{D}$, Lurie N. What is health resilience and how can we build it? Annu Rev Public Health 2015;36:361-74.

9 Booth $\mathrm{A}$, Reed AB, Ponzo S, et al. Population risk factors for severe disease and mortality in COVID-19: a global systematic review and meta-analysis. PLoS One 2021;16:e0247461.

10 Haldane V, De Foo C, Abdalla SM, et al. Health systems resilience in managing the COVID-19 pandemic: lessons from 28 countries. Nat Med 2021;27:964-980.

11 Jöbges S, Vinay R, Luyckx VA, et al. Recommendations on COVID-19 triage: international comparison and ethical analysis. Bioethics 2020;34:948-959.

12 Harris RJ, Hall JA, Zaidi A. Impact of vaccination on household transmission of SARS-COV-2 in England. medRxiv 2021.

13 Masten AS, Motti-Stefanidi F. Multisystem resilience for children and youth in disaster: reflections in the context of COVID-19. Advers Resil Sci 2020:1-12 (published Online First: 2020/08/25).

14 The British Academy. The COVID decade: understanding the longterm societal impacts of COVID-19, 2021. Available: https://www. thebritishacademy.ac.uk/publications/covid-decade-understandingthe-long-term-societal-impacts-of-covid-19/

15 Backhaus I, Sisenop F, Begotaraj E, et al. Resilience and coping with COVID-19: the COPERS study. Int J Public Health 2021;66.

16 Block P, Hoffman M, Raabe IJ, et al. Social network-based distancing strategies to flatten the COVID-19 curve in a postlockdown world. Nat Hum Behav 2020;4:588-96.

17 Johnston RM, Mohammed A, van der Linden C. Evidence of exacerbated gender inequality in child care obligations in Canada and Australia during the COVID-19 pandemic. Pol \& Gen 2020;16:1131-41.

18 Engzell P, Frey A, Verhagen MD. Learning loss due to school closures during the COVID-19 pandemic. Proc Natl Acad Sci U S A 2021;118:e2022376118.

19 Miao Q, Schwarz S, Schwarz G. Responding to COVID-19: community volunteerism and coproduction in China. World Dev 2021;137:105128-28.

20 Chevée A. Mutual aid in North London during the Covid-19 pandemic. Soc Mov Stud 2021:1-7.

21 Abdoul-Azize HT, El Gamil R. Social protection as a key tool in crisis management: learnt lessons from the COVID-19 pandemic. Glob Soc Welf 2020:1-10

22 Rose A. Defining and measuring economic resilience to disasters. Disaster Prev Manag 2004;13:307-14.

23 McDonald L. Household coping behavior and its contribution to resilience to global macroeconomic shocks in Vanuatu and Solomon Islands. Review of Development Economics 2018;22:e185-201.

24 Marchant-Forde JN, Boyle LA. COVID-19 effects on livestock production: a one welfare issue. Front Vet Sci 2020;7:585787.
25 Martin A, Markhvida M, Hallegatte S, et al. Socio-Economic impacts of COVID-19 on household consumption and poverty. Econ Disaster Clim Chang 2020;4:453-79.

$26 \mathrm{Li} \mathrm{Y,} \mathrm{Chen} \mathrm{K,} \mathrm{Collignon} \mathrm{S,} \mathrm{et} \mathrm{al.} \mathrm{Ripple} \mathrm{effect} \mathrm{in} \mathrm{the} \mathrm{supply} \mathrm{chain}$ network: forward and backward disruption propagation, network health and firm vulnerability. Eur J Oper Res 2021;291:1117-1131.

27 Miroudot S. Reshaping the policy debate on the implications of COVID-19 for global supply chains. Journal of International Business Policy 2020;3:430-42.

28 Hyun J, Kim D, Shin S-R. Global connectedness and market power make firms more resilient to domestic COVID-19 shocks, 2020. Available: https://voxeu.org/article/global-connectedness-marketpower-and-firms-resilience-domestic-covid-19-shocks

29 Bartik AW, Bertrand M, Cullen Z, et al. The impact of COVID-19 on small business outcomes and expectations. Proc Natl Acad Sci U S A 2020;117:17656-66.

30 OECD. One year of SME and entrepreneurship policy responses to COVID-19: Lessons learned to "build back better": OECD, 2021. Available: https://www.oecd.org/coronavirus/policy-responses/oneyear-of-sme-and-entrepreneurship-policy-responses-to-covid-19lessons-learned-to-build-back-better-9a230220/

31 Hallegatte S. Economic resilience: definition and measurement. World bank policy research working paper No. 6852. Washington The World Bank; 2014. https://ssrn.com/abstract=2432352

32 Oliu-Barton M, Pradelski BSR, Aghion P, et al. SARS-CoV-2 elimination, not mitigation, creates best outcomes for health, the economy, and civil liberties. The Lancet 2021;397:2234-6.

33 Kumar A, Jain V, et al. Environmental impact of COVID-19 pandemic: more negatives than positives. Environmental Sustainability $2021 ; 728$.

34 Holling CS. Resilience and stability of ecological systems. Annu Rev Ecol Syst 1973;4:1-23.

35 Rutz C, Loretto M-C, Bates AE, et al. COVID-19 lockdown allows researchers to quantify the effects of human activity on wildlife. Nat Ecol Evol 2020;4:1156-9.

36 Haasova S, Czellar S, Rahmani L, et al. Connectedness with nature and individual responses to a pandemic: an exploratory study. Front Psychol 2020;11:2215-15.

37 Kraus S, Koch N. Provisional COVID-19 infrastructure induces large, rapid increases in cycling. Proc Natl Acad Sci U S A 2021;118:e2024399118.

38 Lal R. Home gardening and urban agriculture for advancing food and nutritional security in response to the COVID-19 pandemic. Food Secur 2020:871-6.

39 Liu Z, Ciais P, Deng Z, et al. Near-real-time monitoring of global $\mathrm{CO}_{2}$ emissions reveals the effects of the COVID-19 pandemic. Nat Commun 2020;11:5172.

40 Bova S, Rosenthal Y, Liu Z, et al. Seasonal origin of the thermal maxima at the Holocene and the last interglacial. Nature 2021;589:548-53.

41 Brauner JM, Mindermann S, Sharma M, et al. Inferring the effectiveness of government interventions against COVID-19. Science 2021;371:eabd9338.

42 Hale T, Angrist N, Goldszmidt R, et al. A global panel database of pandemic policies (Oxford COVID-19 government response Tracker). Nat Hum Behav 2021;5:529-38

43 Sebhatu A, Wennberg K, Arora-Jonsson S, et al. Explaining the homogeneous diffusion of COVID-19 nonpharmaceutical interventions across heterogeneous countries. Proc Natl Acad Sci U $S$ A 2020;117:21201-8.

44 Guasti P. The impact of the COVID-19 pandemic in central and eastern Europe. Democratic Theory 2020;7:47-60.

45 Sekalala S, Forman L, Habibi R, et al. Health and human rights are inextricably linked in the COVID-19 response. BMJ Glob Health 2020;5.

46 Noury A, François A, Gergaud O, et al. How does COVID-19 affect electoral participation? Evidence from the French municipal elections. PLoS One 2021;16:e0247026.

47 Peeples L. COVID and the US election: will the rise of mail-in voting affect the result? Nature 2020. doi:10.1038/d41586-020-02979-x. [Epub ahead of print: 23 Oct 2020]

48 Christensen T, Lægreid P, Capacity BG. And legitimacy: how the Norwegian government handled the COVID-19 crisis as a high performer. Public Administration Review 2020;80:774-9.

49 Josephson A, Kilic T, Michler JD. Socioeconomic impacts of COVID-19 in low-income countries. Nat Hum Behav 2021;5:557-65.

50 Stuckler D, Reeves A, Loopstra R, et al. Austerity and health: the impact in the UK and Europe. Eur J Public Health 2017;27:18-21.

51 Young OR. Governing complex systems : social capital for the anthropocene. Kindle ed. Cambridge, MA: The MIT Press, 2017. 